\title{
Scanning Electron Micrographs of Pellets of Aspergillus fumigatus
}

\section{Priyadarshini Dey*}

Indian Institute of Technology Delhi, Hauz Khas, New Delhi, India

*Corresponding author: Priyadarshini Dey, Indian Institute of Technology Delhi, Hauz Khas, New Delhi, India, Tel: 0112659 7135; E-mail: priyadey.lko@gmail.com Rec date: Mar 03, 2015; Acc date: Mar 04, 2015; Pub date: Mar 06, 2015

Copyright: (c) 2015 Dey P, This is an open-access article distributed under the terms of the Creative Commons Attribution License, which permits unrestricted use, distribution, and reproduction in any medium, provided the original author and source are credited.

\section{Clinical Image}
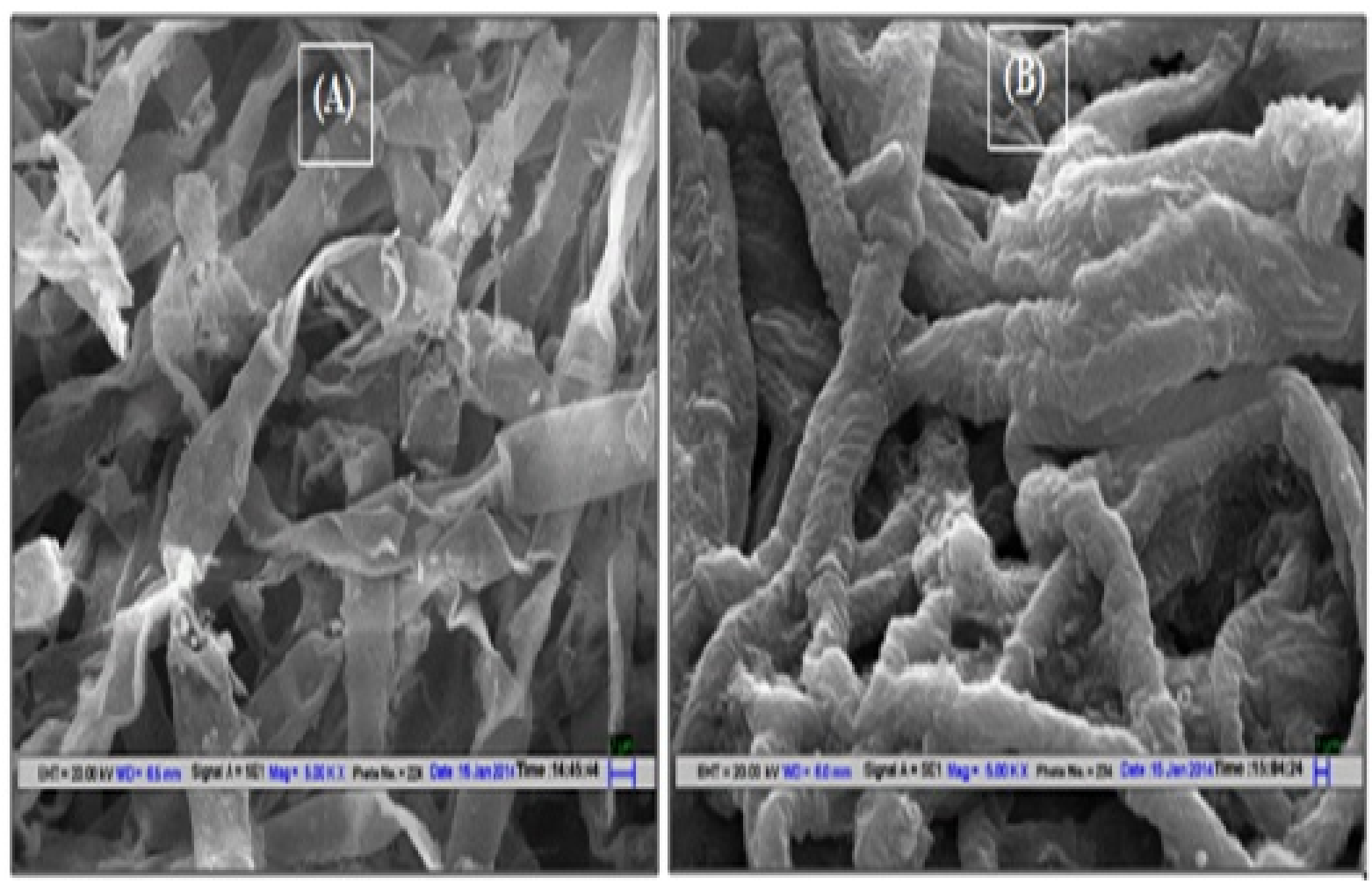

Figure 1: Scanning electron micrographs of pellets of Aspergillus fumigatus. (A) In absence of chromium; (B) $30 \mathrm{mg} / \mathrm{L}$ of Chromium.

In the present study, the bioremediation of metals by microorganisms from contaminated water bodies was studied. The aim was to elucidate the mechanism of uptake of metals from metal amended synthetic media by fungus in particular. In the figures provided,the SEM micrographs reveals a clear distinction between the biotic control and the mycelia stressed with $30 \mathrm{mg} / \mathrm{l}$ of chromium. The fungal hyphae in control is loosely packed and ribbon like than in case of chromium free environment. Highly condensed mycelia were observed particularly in case of $30 \mathrm{mg} / \mathrm{L}$ Chromium. Thus in stressful environment the fungal mycelia aggregates and thus tends to reduce the exposed surface area (Figure 1). 